\title{
Intercropping of climbing bean (Phaseolus vulgaris, L.) and East African highland banana (Musa spp.) in the Ugandan highlands
}

\author{
Esther Ronner ${ }^{1,2, *}$ (D), Eva Thuijsman ${ }^{1}$, Peter Ebanyat ${ }^{2,3}$, Katrien Descheemaeker $^{1}$ and Ken E. Giller ${ }^{1}$ \\ ${ }^{1}$ Plant Production Systems, Wageningen University, P.O. Box 430, 6700 AK Wageningen, The Netherlands, ${ }^{2}$ International \\ Institute of Tropical Agriculture, P.O. Box 7878, Kampala, Uganda and ${ }^{3}$ School of Agricultural Sciences, Makerere University, \\ P.O. Box 7062, Kampala, Uganda \\ ${ }^{\star}$ Corresponding author. Email: esther.ronner@wur.nl
}

(Received 20 March 2020; revised 10 November 2020; accepted 22 December 2020; first published online 17 February 2021)

\begin{abstract}
East African highland bananas and climbing beans are important crops for food and income in the highlands of Uganda. Intercropping of banana with legume crops is a common practice, yet climbing bean intercropping with perennials has rarely been studied in Uganda. To understand how best to improve the production system, we assessed the effects of pruning of banana leaves on light availability for climbing beans, resulting effects on bean yields and potential differences in shade tolerance between two climbing bean varieties in the eastern and southwestern highlands of Uganda. Measurements of the transmission of photosynthetically active radiation (PAR) through the banana canopy were combined with yield measurements of a local and improved climbing bean variety and with banana pseudostem girth in two seasons (2016A and 2016B). We also compared yields of intercropped with sole-cropped climbing beans. The mean fractions of PAR transmitted through the banana canopy - hence available for beans - were 0.43 on pruned and 0.38 on non-pruned subplots, a significant $15 \%$ difference. The improved light availability did not increase climbing bean yield. Although no direct relationship between light interception and bean yields was found, bean yields on the most and least shaded parts of the intercropped fields differed significantly, suggesting that beans do benefit from improved light availability in intercropping. Generally, yields of sole-cropped beans were significantly larger than of intercropped beans, but we could not single out the effects of competition for light, water, and/or nutrients. The bean varieties responded similarly to the pruning treatments. The local variety tended to perform relatively better in intercropping, the improved variety in sole cropping, though differences were not significant overall. Pruning and retention of eight banana leaves over the course of a season did not affect banana pseudostem girths in the mature banana plantations. Although light availability improved, farmers may not expect a major effect on bean yield. Future research may focus on the effects of a lower number of leaves retained, comparing a number of bean varieties for suitability in sole or intercropping, or on other factors influencing the relation between the two crops such as relative plant densities of beans and bananas.
\end{abstract}

Keywords: Systems agronomy; legumes; East Africa

\section{Introduction}

The integration of legumes in farming systems provides a pathway for sustainable intensification of agriculture (Giller and Cadisch, 1995; Snapp et al., 2002; Vanlauwe et al., 2019). In East Africa, common bean (Phaseolus vulgaris L.) is an important staple crop and a source of protein, calories, 
minerals, and vitamins. Compared with the commonly grown bush bean varieties, climbing beans offer potential to intensify bean production. Their yield potential is their main advantage, with yields of climbing bean of up to 4-5 tons ha ${ }^{-1}$ (Checa et al., 2006), compared with 1-2 tons ha ${ }^{-1}$ for bush beans in Uganda (Kaizzi et al., 2012). From the 1980s, the use of improved varieties of climbing beans spread rapidly in Rwanda (Sperling and Muyaneza, 1995) and then to neighboring countries such as Burundi, DRC, and Uganda.

Studies focusing on the productivity of climbing beans in East Africa often consider beans as sole crops (Franke et al., 2016; Kaizzi et al., 2018), or in intercropping with maize (Gebeyehu et al., 2006; Isaacs et al., 2016). However, in the eastern and southwestern highlands of Uganda, 50-75\% of farmers intercrop climbing beans with East African highland banana (Musa spp.; henceforth called banana) or a mixture of coffee (Coffea arabica L.) and banana (Ronner et al., 2018). With land scarcity as an important reason for intercropping, this practice is likely to continue in future.

Yet, there are few reports on the intercropping of climbing beans with perennials. To our knowledge, only three studies, all in DRC, focused on banana and climbing bean intercropping (Ntamwira et al., 2013; 2014; Ocimati et al., 2019). These three studies considered the effect of banana leaf pruning to increase light availability for legume intercrops, including climbing beans. Ntamwira et al. (2013) was conducted on-station and focused on three levels of pruning: all, seven, and four banana leaves retained. The authors found no effect of pruning on climbing bean yields with pruning up to seven leaves remaining. When four banana leaves were retained, climbing bean yields increased but banana pseudostem circumference - which shows a relation with banana bunch weight (Nyombi et al., 2009; Wairegi et al., 2009) - reduced. Ntamwira et al. (2014) carried out a similar experiment on-farm, with two pruning levels (all and seven banana leaves retained) and a comparison between a local and an improved variety of climbing bean. This study showed mixed results with respect to yield improvements of climbing beans depending on banana plant density, soil fertility, and bean variety. It was concluded that on more fertile fields, banana plants grew more vigorously, hence reducing the amount of light for the intercropped legumes. On less fertile soils, smaller but more densely planted bananas overall caused less shading. The improved climbing bean variety gave smaller yields than the local variety in intercropping, whereas in sole cropping the improved variety performed better. Ocimati et al. (2019) followed up with a study on the required banana leaf pruning intensity to optimize productivity of the intercrops, including land equivalent ratios and net revenues. Pruning with seven leaves retained reduced banana yields in the climbing bean intercrop treatment, and net revenues were smaller than without pruning because of the high value of banana produce and the additional labor involved in pruning. However, the study did not report on the effects of pruning on climbing bean yield specifically. Hence, while severe pruning clearly affects banana yields and profitability, the (on-farm) effects of more moderate pruning levels on climbing bean yields are inconclusive.

In Uganda, farmers also prune their bananas to enable light penetration to the understory crop. When plant spacing is wide $(3 \times 3 \mathrm{~m}), 8-10$ leaves are retained, and with closer spacing $(2 \times 2 \mathrm{~m}$ or less) this may be reduced to 5-7 leaves (P. Nyokos, F. Mutai, personal communication). The effects of pruning on these crops in farmers' fields have not been studied in the country. We have three reasons to assume that the results of the studies in DRC are not directly applicable to Uganda. First, the soils in the eastern and southwestern highlands of Uganda have more favorable soil properties than the soils described in Ntamwira et al. (2014) (cf. Marinus, 2015). Hence, with larger banana plants, the effect of banana leaf pruning on climbing bean yields is expected to be more pronounced. Second, two of the three studies were carried out on-station, with a uniform banana plant density. On farmers' fields, distances may be smaller or larger than recommended, and hence influence the effect of pruning. Third, as this study was carried out in the context of a legume project that had recently introduced a new variety of climbing bean (Ronner et al., 2018) different than the varieties grown in DRC - we wanted to assess the shade tolerance of this variety versus a local variety. Farmers had commented that their local bean varieties "did not fear shade," 
and Isaacs et al. (2016) found that farmers favored different attributes of climbing bean varieties in their selection for intercropping with maize than for sole-cropped climbing beans. In the end, when climbing beans are largely grown as intercrops, farmers will likely base (part of) their decision to adopt a new variety on its performance in intercropping compared with the old variety.

An experiment on climbing bean and banana intercropping was therefore conducted on farmers' fields in the eastern and southwestern highlands of Uganda. We assessed the effects of pruning versus non-pruning in mature banana on yields of climbing bean. A local and an improved variety of climbing bean were compared, and we hypothesized that 1) climbing bean grain yield is positively affected by banana leaf pruning due to improved light availability and 2) differences in shade tolerance of climbing bean varieties determine their suitability for use in intercropping with banana.

\section{Methods}

\section{Site selection}

The experiment was established in Kapchorwa district in the eastern highlands (between $34.30^{\circ}$ and $34.55^{\circ}$ East and $1.18^{\circ}$ and $1.50^{\circ}$ North) and Kanungu district in the southwestern highlands of Uganda (between $29.69^{\circ}$ and $29.86^{\circ}$ East and $-1.07^{\circ}$ and $-0.89^{\circ}$ South), both located at an altitude of about 1800-1900 $\mathrm{m}$ above sea level. The districts have two rainy seasons per year, with an average annual rainfall of $1600 \mathrm{~mm}$ in Kapchorwa and $1200 \mathrm{~mm}$ in Kanungu. Soils in Kapchorwa are Nitisols and in Kanungu Acrisols and Andosols, with soil properties being relatively poorer in Kanungu than in Kapchorwa (lower pH, available P, K, Ca, and Mg) (Marinus, 2015).

The experiments were conducted in the first and second rainy season of 2016 (seasons 2016A and $\mathrm{B}$, respectively) and took place on-farm in existing banana home gardens. Banana home gardens were selected if they were relatively well-managed in terms of application of household waste and/or manure (to presume uniform management conditions), if they contained only banana plants (no coffee or other crops), and if banana plants looked healthy (i.e., not affected by nematodes or other pests or diseases). Banana home gardens were selected if they contained early or mid-maturing varieties (most farmers grew a mixture of varieties on the same field) and if the plants were older than 1 year to ensure flowering during the experiment, which would allow for allometric measurements relating to banana bunch weights (Nyombi et al., 2009; Wairegi et al., 2009). Densities of banana mats varied in the selected home gardens and this was accounted for by using mat density as a covariate in the analysis. The selected fields also had a piece of open land adjacent to it, which allowed for the establishment of two plots with sole crops of a local and improved climbing bean variety. No fields of sole-cropped banana were included, because it was assumed that banana yields were not affected by a climbing bean intercrop (Ntamwira et al., 2014; Wortmann et al., 1992), although the recent study of Ocimati et al. (2019) did find a significant decrease in bunch weight from the climbing bean intercrop after multiple seasons. In Kapchorwa, 13 trials were established in 2016A and 10 in 2016B, and in Kanungu 15 in 2016A and 14 in 2016B. Each farm hosted one unreplicated trial; hence, each farm represents one replicate.

\section{Experimental design and management}

Each experimental field within a farm covered an area of $12 \times 12 \mathrm{~m}$, consisting of four subplots of $6 \times 6 \mathrm{~m}$ in a split-plot design with two levels of pruning and two climbing bean varieties, and two separate plots of $6 \times 6 \mathrm{~m}$ with the sole-cropped bean varieties (Supplementary Material Appendix I). Pruning on the intercropped plots implied that all banana leaves were removed except the eight youngest leaves from the top. We tested this single pruning level which matches the moderate pruning levels practiced by farmers who intercrop their bananas. Retaining eight leaves was assumed not to affect banana yields, based on the earlier studies in DRC and experience in Uganda (G. Taulya, personal communication), but was still hypothesized to enhance light 
availability for beans. Pruning was done every 2 weeks, starting at planting of the beans. No pruning implied that all leaves were retained (varying from 9 to 11 green leaves). The local climbing bean varieties included in the experiment were NABE 10C in 2016A (released in 1999 and referred to as local varieties by farmers: "Atawa" in Kapchorwa and "Mubano" in Kanungu) and variety NABE 8C in 2016B (also released in 1999 and called "Kabweseri" in Kanungu). In both seasons, NABE 12C (released in 2005) was planted as the improved climbing bean variety. All bean varieties were type IV (indeterminate) varieties and were supported by one stake per two plants. NABE 10C takes 85-100 days to mature, NABE 8C 80-110 days, and NABE 12C 90-110 days (MAAIF, 2019).

Climbing beans were planted at a spacing of $50 \mathrm{~cm}$ between rows, and $25 \mathrm{~cm}$ between plants, which is recommended for climbing beans in sole cropping. For comparability, the same spacing was applied in the intercropped plots. In practice, farmers may plant intercrops at a wider spacing, but because legume intercrops have limited impact on banana yields, maintaining planting densities was assumed to maximize bean production if shading on the beans is reduced. Each plot then accommodated 11 rows of climbing bean, but the total number of bean plants per plot in intercropping varied with banana plant density. Each subplot contained about three to ten banana mats, depending on the farmer's practice.

The experiment was implemented and monitored by field assistants. The field assistants took care of the pruning of bananas and instructed farmers when to weed their fields (twice per season). Farmers themselves managed the number of banana pseudostems per mat.

\section{Light transmission measurements}

Photosynthetically active radiation (PAR) was measured with use of the AccuPAR LP-80 (Decagon Devices Inc., Pullman, Washington, USA), shortly after planting beans and before staking, once per season in each of the subplots in 2016A and 2016B. Measurements of incident PAR were taken in a non-shaded area next to the banana field (the plants were too large to bring the sensor above the canopy). PAR levels were also measured below the banana canopy, but above the bean canopy, to capture what fraction of incident PAR was transmitted through the banana canopy and available for beans. The measurements were conducted before the beans were staked for ease of passage through the field, and no major differences in light penetration through the banana canopy were expected over the course of the season. The timing of measurements was between $10 \mathrm{am}$ and $2 \mathrm{pm}$, and as much as possible under uniform conditions: either clear skies or uniform overcast skies.

PAR measurements in between the banana and bean canopy were taken along two perpendicular straight transects per subplot (Supplementary Material Appendix II). The transects were positioned along a row of banana plants, such that they passed banana plants at a distance of $0.5 \mathrm{~m}$ from the stem. Measurements were taken at intervals of $0.5 \mathrm{~m}$ along the transects, holding the AccuPAR probe perpendicular to the transect. Along with each measurement, field assistants recorded whether that position was fully, partly, or not covered by the banana canopy by looking upwards and judging whether they saw only banana canopy (fully covered), only the sky (not covered), or both (partly covered). At every measurement position, five PAR readings were taken rapidly after each other. The average was recorded for that position. Incident PAR measurements outside the canopy were taken every time a new (below-canopy) transect was started.

\section{Climbing bean harvest}

Before harvesting the whole subplot, climbing bean yields on intercropped subplots in Kanungu were assessed for two strips of approximately $1 \times 2 \mathrm{~m}$ : the least and the most shaded parts of the subplot. The exact orientation and size of those strips were determined based on the positions of banana mats in each subplot, and they always covered (parts of) two rows of beans without any 
banana mats in it (Supplementary Material Appendix I). These strips served two purposes: 1) an additional assessment of the effect of light availability on climbing bean yield (difference in bean yield between the most and least shaded strip) and 2) a comparison with the sole-cropped climbing bean yield, as the strips did not have any banana plants in them and therefore had the same plant density as the sole-cropped subplots (difference in bean yield between shaded beans in intercropping and non-shaded beans as sole crops).

The yields of the two strips and of the remainder of the subplot together established the total climbing bean yield per subplot, for the assessment of bean yields per treatment and the assessment of differences between sole and intercropped beans including the reduction in plant population as a result of the banana intercrop. In Kapchorwa and on the sole-cropped bean subplots, only total yields of the whole subplot were assessed. All yields were reported as shelled, air-dried weights.

\section{Banana measurements}

The girth of the pseudostem base was recorded once for each banana plant per plot being in reproductive stage (flowering to harvest). Checks of banana plants entering the reproductive stage happened at regular intervals throughout the growing season. Banana pseudostem circumference shows an allometric relation with banana bunch weights (Nyombi et al., 2009; Wairegi et al., 2009) and was used as an indication of any potential differences arising in banana production levels between the pruned and non-pruned plots. Pseudostem girth measurements starting from 2 months after the first pruning up to the end of the bean growing season were included.

The number of banana mats was recorded per plot. The distance between the banana mats in each plot, as well as the number of pseudostems per mat, was only recorded in 2016B. Field assistants also recorded the names of banana varieties grown in each plot and judged their leaf angles: erect, horizontal, or in between.

\section{Field challenges}

In season 2016A, only 5 out of 15 trials in Kanungu could be harvested - some climbing bean trials were planted late and failed to yield because of a dry spell in May, others were destroyed by hail, and 1 trial had no banana plants left as a result of Banana Xanthomonas Wilt. In Kapchorwa, 8 out of the 13 trials were harvested. The other trials were harvested by farmers themselves before recordings were taken. In the harvested trials, still some individual treatments failed to yield because of a dry spell towards the end of May, disease affecting the beans or animals damaging the field. Also in season 2016B, bean yields in Kapchorwa were completely destroyed as a result of a drought in the middle of the season. Therefore, only PAR measurements were taken and yield data and other agronomic measurements for $2016 \mathrm{~B}$ were only available for Kanungu.

\section{Statistical analysis}

Linear mixed models were used to test differences in PAR transmission and crop yield between treatments. For PAR, a full set of data was available for Kapchorwa and Kanungu in 2016A and B. A model with farms as random factor and year and district as fixed factors was used to assess the overall effect of pruning on PAR transmitted:

$$
\mathrm{PAR} \sim \text { year } * \text { district } * \text { pruning }+(1 \mid \text { farm })
$$

Agronomic data was missing for Kapchorwa 2016B (see "Field challenges"). A subset with combinations of PAR and agronomic data was therefore considered, in which the number of mats per plot (mean-centered) was included as a co-variable potentially influencing PAR. Year and district were combined in a single variable (year_district) to account for the imbalance in data: 


$$
\text { PAR year_district }+ \text { mats_per_plot }+ \text { pruning }+(1 \mid \text { farm })
$$

Climbing bean yields were assessed with the same subset of data. Bean yields were square-root transformed to ensure homoscedasticity of residuals. In case of interactions between year_district and treatments, the interaction was accounted for in the random part of the model, for instance:

$$
\text { yield } \sim \text { mats_per_plot }+ \text { variety } * \text { pruning }+ \text { (variety }+ \text { pruning|year_district })+(1 \mid \text { farm })
$$

To account for differences in the farmer-managed number of pseudostems per mat, a factor "pseudostems per plot" was derived from multiplying the number of mats per plot with the average number of pseudostems per mat in each plot. A model with this factor as co-variable (instead of the number of mats per plot) was tested for PAR and climbing bean yield in Kanungu 2016B.

$$
\begin{gathered}
\text { PAR } \sim \text { pseudostems_plot }+ \text { pruning }+(1 \mid \text { farm }) \\
\text { yield } \sim \text { pseudostems_plot }+ \text { variety } * \text { pruning }+(1 \mid \text { farm })
\end{gathered}
$$

Differences between the sole and intercropped bean yields were assessed with:

$$
\text { yield } \sim \text { sole_inter } * \text { variety } * \text { pruning }+(1 \mid \text { year_district })+(1 \mid \text { farm })
$$

And the effect of PAR on climbing bean yields with:

$$
\text { yield } \sim \text { mats_per_plot }+ \text { PAR } * \text { pruning }+(1 \mid \text { year_district })+(1 \mid \text { farm })
$$

A Chi-square test was used to assess differences between the number of measurement points classified as fully, partly, or not covered among pruned and non-pruned plots. Software used was R Version 3.4.1 (2017).

\section{Results}

\section{Light availability for beans}

The mean fractions of PAR transmitted through the banana canopy - hence available for beans over all positions and transects were significantly larger in pruned subplots than in non-pruned subplots (Eq 1, $p<0.001$ ). There was no significant year or district effect. Mean fractions of PAR transmitted through the bananas canopy across seasons and districts were 0.43 (SE $=0.01, n$ $=1560)$ and $0.38(\mathrm{SE}=0.01, n=1543)$ on pruned and non-pruned plots, respectively (Figure 1). Light transmission profiles recorded along the transects for each farm are available in Supplementary Material Appendix III.

Including the number of banana mats per plot (mean: 5.2 mats, SE: 0.21 , min:3, max: 10) as co-variable in the subset with agronomic data did not change the results, and the number of mats per plot had no significant effect on the fractions of PAR transmitted through the banana canopy (Eq 2). However, an increasing number of pseudostems per plot (in Kanungu 2016B, mean 13.7 pseudostems per plot, SE: 0.8 , min: 7, max: 23) significantly reduced the fraction of PAR transmitted $(p<0.05)$ and resulted in a smaller difference between the pruned and non-pruned plots (Eq $4, p=0.08)$. The presence of banana cultivars with different leaf angles could have contributed to differences in light interception between farms. Bananas in Kapchorwa were dominantly classified as having erect banana leaves, and in Kanungu mostly horizontal or in between. However, farmers grew a mixture of (up to five) banana cultivars on their plot, and the majority of fields had a mixture of leaf angle classifications. No estimate was made of the area under different banana cultivars; hence, these data could not be related to PAR measurements.

Every position along each transect was classified as being fully, partly, or not covered by the banana canopy. Besides large variation in PAR fraction within each class of canopy cover, the fractions transmitted through the banana canopy were significantly different between all coverage classes in both seasons and districts $(p<0.001)$ (Figure 2). Canopy cover classifications did not differ between the pruned and non-pruned plots, except for Kapchorwa in season 2016B $(p<0.01)$ : 
(a)

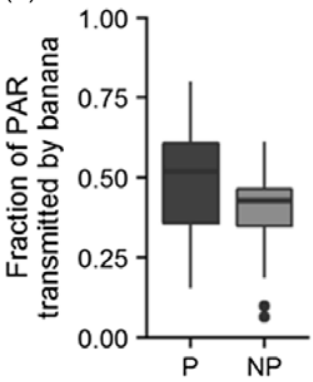

2016A, Kapchorwa (b)

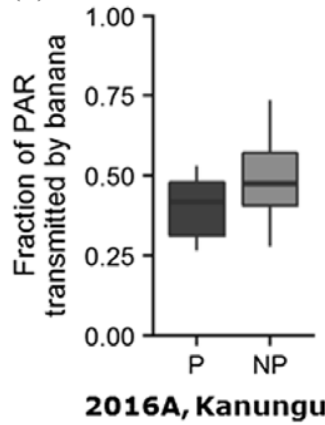

(c)

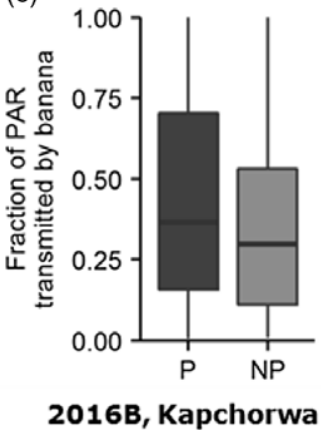

(d)

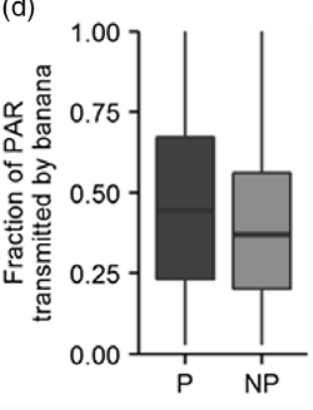

2016B, Kanungu

Figure 1. Fractions of incident PAR transmitted through the banana canopy in pruned $(\mathrm{P})$ and non-pruned (NP) treatments in 2016A ( $a$ and b) and 2016B ( $c$ and d) in Kapchorwa ( $a$ and $c$ ) and Kanungu ( $b$ and d).

(a)

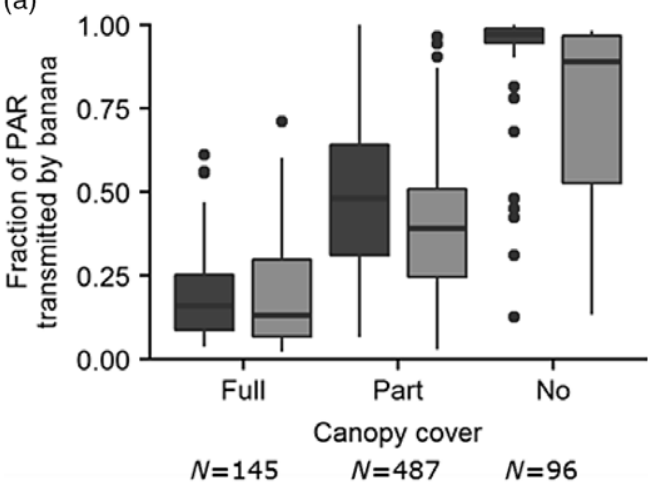

(c)

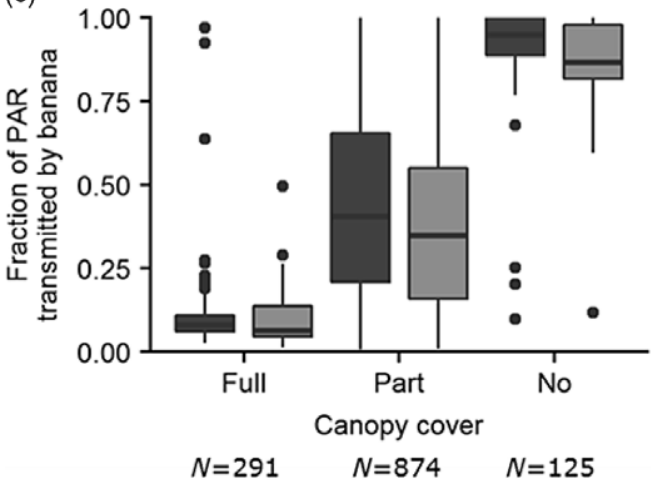

(b)

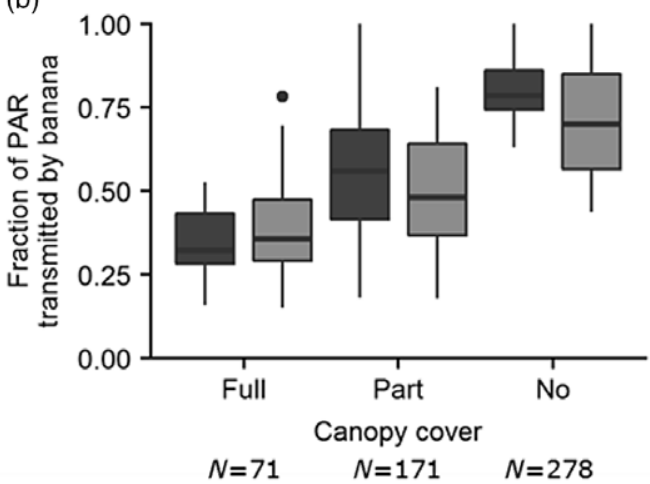

(d)

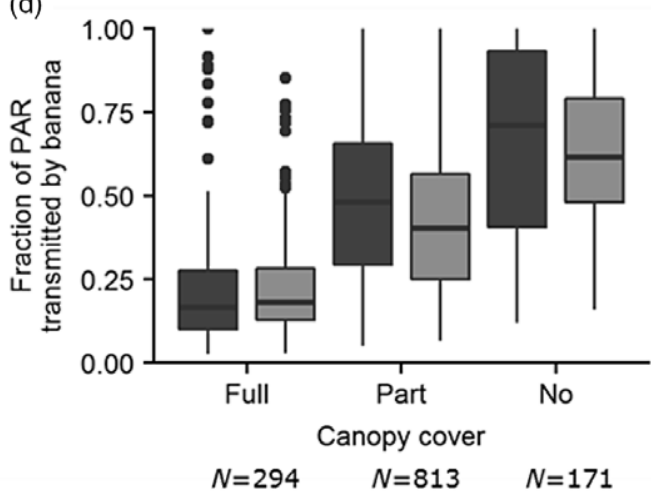

Pruning management

\section{Pruning \\ 它 No pruning}

Figure 2. Fractions of incident PAR transmitted by the banana canopy on positions that were classified as being fully, partly, or not covered by banana plants in Kapchorwa ( $a$ and c) and Kanungu ( $b$ and d) in seasons 2016A (a and b) and $2016 \mathrm{~B}$ (c and d). 
Table 1. Canopy cover classifications in pruned and non-pruned banana canopies in Kanungu and in Kapchorwa in 2016A and 2016B

\begin{tabular}{|c|c|c|c|c|c|c|}
\hline \multirow[b]{3}{*}{ Pruning treatment } & \multicolumn{6}{|c|}{ Banana canopy cover classifications ( $\%$ of treatment $\mathrm{N}$ ) } \\
\hline & \multicolumn{3}{|c|}{ Kapchorwa } & \multicolumn{3}{|c|}{ Kanungu } \\
\hline & Full & Part & No & Full & Part & No \\
\hline \multicolumn{7}{|l|}{$2016 A$} \\
\hline Pruned & 19 & 67 & 13 & 12 & 32 & 57 \\
\hline Non-pruned & 21 & 66 & 13 & 15 & 34 & 50 \\
\hline \multicolumn{7}{|l|}{$2016 B$} \\
\hline Pruned & 14 & 66 & 20 & 19 & 67 & 13 \\
\hline Non-pruned & 18 & 78 & 4 & 26 & 62 & 12 \\
\hline
\end{tabular}

Table 2. Mean climbing bean grain yield per pruning treatment and variety in Kapchorwa (2016A) and Kanungu (2016A and B). Local = variety NABE10C in 2016 and NABE8C in 2016B, improved = variety NABE $12 \mathrm{C}$

\begin{tabular}{|c|c|c|c|c|}
\hline \multirow[b]{3}{*}{ Treatment } & \multirow[b]{3}{*}{ Variety } & \multicolumn{3}{|c|}{ Yield $\left(\mathrm{kg} \mathrm{ha}^{-1}\right)$} \\
\hline & & Kapchorwa 2016A & Kanungu 2016A & Kanungu 2016B \\
\hline & & Mean \pm SE $(n)$ & Mean \pm SE $(n)$ & Mean \pm SE $(n)$ \\
\hline No pruning & Improved & $125 \pm 33(6)$ & $551 \pm 98$ & $1018 \pm 181(12)$ \\
\hline Pruning & Improved & $397 \pm 246$ & $371 \pm 71$ (5) & $1274 \pm 328(12)$ \\
\hline No pruning & Local & $134 \pm 32(6)$ & $1051 \pm 225$ & $1050 \pm 135(12)$ \\
\hline Pruning & Local & $255 \pm 101(6)$ & $783 \pm 172(5)$ & $1101 \pm 209$ \\
\hline Sole cropping & Improved & $165 \pm 8(8)$ & $1157 \pm 133$ & $1676 \pm 188(10)$ \\
\hline Sole cropping & Local & $179 \pm 9(7)$ & $1838 \pm 260$ & $1393 \pm 240(12)$ \\
\hline
\end{tabular}

the non-pruned plots had a larger percentage of full and partly covered measurement points; the pruned plots had relatively more points without cover (Table 1). Levels of PAR transmitted differed most between pruned and non-pruned plots under partial cover ( 0.48 vs 0.41 on pruned and nonpruned plots, $p<0.001)$, and less so under no $(0.79$ vs $0.70, p<0.05)$ and full cover (not significant).

\section{Bean yields}

Climbing bean yields did not differ significantly between the pruned and non-pruned plots (Eq 3, Table 2). Yields of the local and improved variety did not differ either (Eq 3), except for Kanungu in $2016 \mathrm{~A}$ where the local bean variety had a significantly larger yield than the improved variety $(p<0.001)$. Bean yields were significantly larger in Kanungu (both seasons) than in Kapchorwa $(p<0.01)$. The differences in bean yield between season 2016A and 2016B in Kanungu were not significant. The number of mats per plot (Eq 3) or the number of pseudostems per mat (Eq 5) had no significant effect on bean yields.

Overall, yields of sole-cropped beans were significantly larger than that of intercropped beans (Eq 6), with the exception of the pruned plots in Kapchorwa which had larger yields than the solecropped beans (Table 2). The observed differences in yield of sole and intercropped beans suggest that improved light availability increases bean yields. However, the differences could also be the result of differences in plant densities rather than shading alone, as the positions of banana plants interrupted rows of beans. We therefore also compared the mean yield of the least and most shaded strips (without banana plants) in Kanungu with the sole-cropped bean yields. Overall, the mean yield of the least and most shaded strips did not differ significantly from that of the sole crop, but this was largely the result of an interaction with year: yields of the sole beans were 


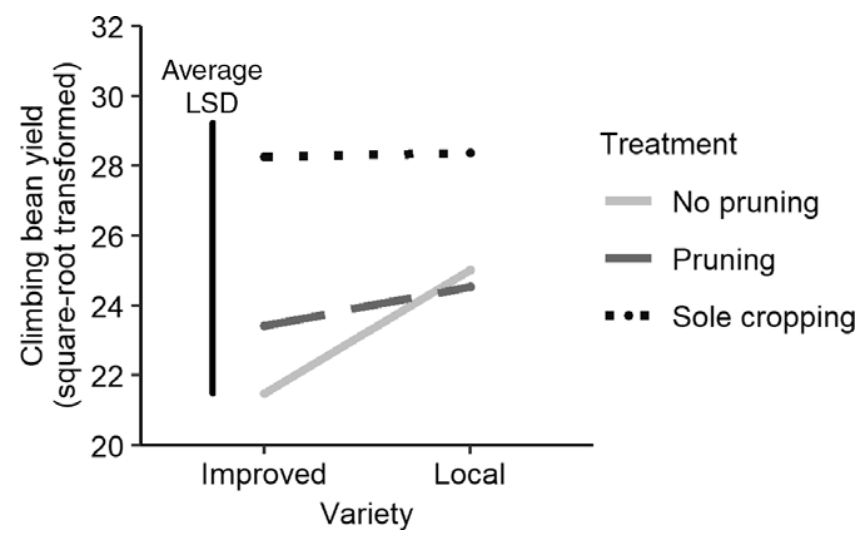

Figure 3. Predicted mean bean yields per variety (improved and local) and treatment (no pruning, pruning, and sole cropping). Average LSD bar indicates significant differences $(p<0.05)$.

smaller than yields on the most and least shaded parts of the intercropped fields in 2016A, and larger in 2016B (data not presented).

Overall, the local and improved variety yielded similarly in sole cropping (977 vs $958 \mathrm{~kg} \mathrm{ha}^{-1}$ for the local and improved variety, respectively). Only in Kanungu 2016B, the improved variety yielded significantly more than the local variety in sole cropping $(p<0.001)$. In intercropping, however, the local variety tended to yield more than the improved variety (average of 774 vs $588 \mathrm{~kg} \mathrm{ha}^{-1}$ ). Also, the local variety performed relatively better in non-pruned than in pruned plots (Figure 3). These differences were not significant, however, and partly the effect of the larger yields of the local variety in Kanungu in 2016A (Table 2).

\section{Relationship between light availability and bean yields}

The average PAR transmitted on the pruned and non-pruned plots showed no relationship with climbing bean yields (Eq 7). Hence, although the fraction of PAR transmitted was larger on the pruned subplots, this did not result in an increase in bean yield.

However, bean yields for plants on the least shaded strips of the plots were significantly larger than for plants on the most shaded strips in Kanungu in 2016A and 2016B (Figure 4), suggesting that larger light availability improves bean yield after all. Yields on the most and least shaded parts of the plots were not significantly different for the pruning or variety treatments.

\section{Banana pseudostem circumference}

The mean girth of the base of the banana pseudostems was $43 \mathrm{~cm}$ in Kapchorwa in 2016A, and 70 and $42 \mathrm{~cm}$ in Kanungu in 2016A and B, respectively. Pseudostem circumference differed significantly between the districts, but not between the pruned and non-pruned banana subplots.

\section{Discussion}

\section{Did pruning improve climbing bean yields?}

Pruning of mature banana plants was expected to increase light transmission through the banana canopy. The fraction of PAR transmitted was 0.38 on the non-pruned and 0.43 on pruned plots, a significant $15 \%$ increase. The fractions fell within the range of $0.30-0.50$ of PAR transmitted observed by Nyombi et al. (2009) in mature banana. The $15 \%$ increase was also in line with findings of Ntamwira et al. (2013), who recorded a $20 \%$ increase in PAR with banana pruning up to 
(a)

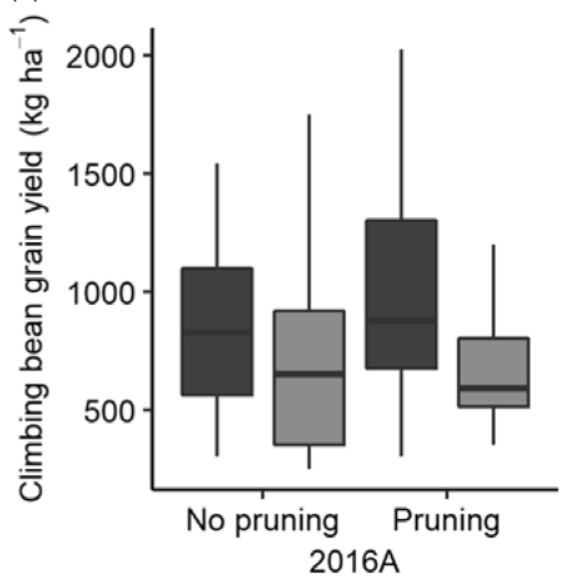

(b)

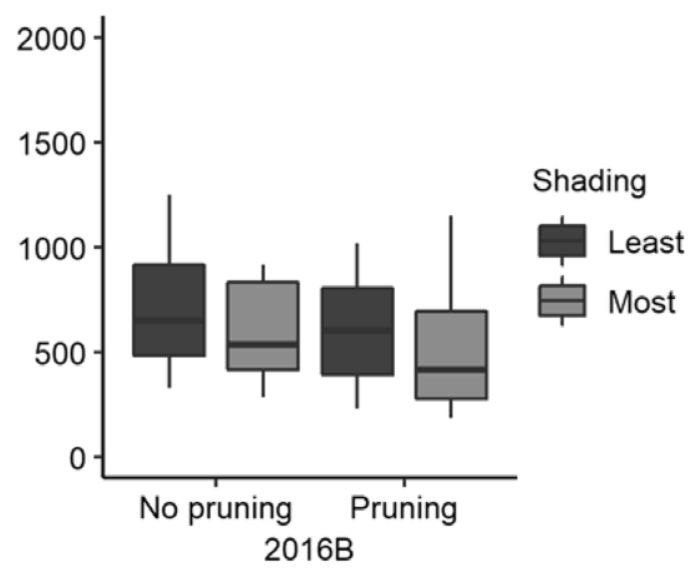

Figure 4. Climbing bean grain yields on least and most shaded parts of the non-pruned and pruned plots in Kanungu in 2016A $(n=5)$ and 2016B $(n=14)$.

seven leaves remaining. No direct relationship was found between the amount of light transmitted and climbing bean yields. However, when comparing the least shaded and the most shaded strips of each field in Kanungu, bean yields were significantly larger on the least shaded strips (Figure 4). Overall, pruning increased light transmission through the banana canopy, but there was only weak evidence that reduced shading positively affected climbing bean yields and no significant effects of pruning on climbing bean yields.

Our findings suggest that pruning may not have been severe enough to enhance climbing bean yields. The fraction of PAR transmitted through the banana canopy on the pruned plots was 0.43 , whereas Akyeampong et al. (1999) concluded that a similar fraction of 0.42 of PAR transmitted decreased bush bean yields by $27 \%$ compared to a non-shaded control. For climbing bean, internal shading of the bean plants could have reduced light availability even more than is expected in bush bean, which could have contributed to a limited effect of pruning on yield. However, Ntamwira et al. $(2013$; 2014) found similar (small) effects of pruning on bush and climbing bean yields. A fraction of 0.70 of total PAR transmitted did not affect bean yields in a study by Akyeampong et al. (1999), and this fraction is similar to the fraction found in the non-covered measurement positions (Figure 2).

However, at a more severe pruning regime with only four banana leaves remaining, Ntamwira et al. (2013) and Ocimati et al. (2019) found that banana yields significantly reduced, and in the latter study even pruning up to seven leaves remaining reduced banana yields. We therefore decided to retain eight leaves and to prune for the duration of the bean growing season (4 months) only. No effect on banana yield was therefore expected, which was confirmed by the lack of difference between banana pseudostem circumferences. An optimal balance between the two crops therefore also requires considering the relative importance of beans versus bananas. Ocimati et al. (2019) concluded that, given the larger economic value of banana compared with beans, pruning up to seven leaves resulted in larger net profits than pruning to four leaves, because of the reduction in banana yield (with the relative price differences being comparable to prevailing market prices at the time of our study).

Climbing bean yields were larger in the sole crop than in the intercrop, in line with findings of Ntamwira et al. (2013) and Wortmann et al. (1992) for banana and bush bean intercropping. This indicates that bean yields were reduced by the competition with banana for light, water, and/or nutrients. However, in this study we could not determine which factor was the most important. Although mean yields of the most and least shaded strips did not differ from the sole-cropped yields, this was largely the result of seasonal effects: larger yields were found for inter- rather than 
sole-cropped beans in 2016A and smaller yields for inter- rather than sole-cropped bean in 2016B. Because these strips only measured $1 \times 2 \mathrm{~m}$, their conversion to $\mathrm{kg} \mathrm{ha}^{-1}$ risks large error margins. This makes the latter comparison between sole and intercropping less reliable than the comparison based on the yields of the entire subplots. A comparison based on bean yields per plant rather than on an area basis could reduce this error margin.

\section{How did pruning and intercropping affect variety performance?}

It was expected that the local and improved bean variety would differ in their shade tolerance and suitability for intercropping, and therefore give different yields in sole or intercropping, and in pruned and non-pruned treatments. Pruning did not affect the performance of the local and improved variety. In some instances, the local variety performed better than the improved variety: in Kanungu in 2016A and in inter- compared with sole-cropped plots (Figure 3), although the latter difference was not significant. In sole cropping, the improved variety yielded significantly more than the local variety in 2016B, but not in 2016A. No differences in bean yield between the local and improved variety on the most and least shaded plots were found. All in all, these findings suggest that the local variety performed relatively better in intercropping, and the improved variety relatively better in sole cropping. This is in line with findings of Ntamwira et al. (2014), but a study over multiple seasons would have to confirm these results.

The lack of an effect of pruning on variety performance is in contrast to the observations of Ntamwira et al. (2014), as they found that local climbing bean varieties benefitted more from banana pruning than improved varieties. Wortmann and Sengooba (1993) found no differences between different bush bean varieties grown in intercropping with banana. In climbing bean and maize intercropping systems, Davis and Garcia (1983) found that the most competitive bean varieties in intercropping were taller, more vigorous, and later maturing varieties, and not necessarily the best yielding varieties in monocropping. As these varieties also provided direct competition with maize, Isaacs et al. (2016) concluded that farmers identified varieties with restricted height and early maturity as more suitable for intercropping. With maize, however, climbing beans tend to be more dominant and could therefore show stronger differences between varieties than climbing beans in systems where banana dominates (cf. Wortmann and Sengooba, 1993).

\section{Other factors influencing bean yields}

Next to pruning, a lower density of banana mats could improve light availability and result in larger bean yields. However, we found no relationship between the number of banana mats and PAR availability for beans. On the one hand, this may be explained by the method for choosing the positions for the transects: the transects were always chosen next to a row of banana plants and not at a random position in the field. Transects were therefore rarely positioned below large gaps in the banana canopy. The distance between banana plants was relatively large in our study (almost 3 vs $2 \mathrm{~m}$ in Ntamwira et al., 2013, 2014; Ocimati et al., 2019). This larger spacing will probably have resulted in a larger light availability overall, and reduce the effect of pruning compared with the three studies in DRC. On the other hand, farmers retained a varying number of pseudostems on the banana mats. Fewer mats would probably have a larger number of pseudostems (because of the larger space available between mats, and in line with the practice of retaining more leaves per plant), which would explain the stronger relation between the number of pseudostems per plot and PAR than mat density only.

Considering the differences in average rainfall and soil fertility between the eastern and southwestern highlands, both climbing bean and banana yields were expected to be larger in Kapchorwa than in Kanungu. This was not the case, although yields were only available for Kapchorwa in 2016A. The yields in Kapchorwa in 2016A were heavily affected by drought, which also explains 
why yields appear small in comparison with findings in other studies (Franke et al., 2016; Ntamwira et al., 2013; Ronner et al., 2018).

\section{Field challenges and recommendations for future research}

There was considerable variation in PAR availability across transects through subplots (Supplementary Material Appendix III). This was a result of shading by banana trees, but also of fluctuations in incident PAR. Some measurements of below-canopy PAR were larger than the value of incident PAR measured outside of the canopy. These values were set to 1 , but they indicate that the incident PAR had sometimes increased during the taking of measurements below the canopy. If incident PAR increased or decreased during the below-canopy measurements, for instance as a result of clouds passing by, PAR availability would be over- or underestimated, respectively. Ideally, PAR measurements above and below the canopy should be taken simultaneously, with use of two sensors to avoid this problem (Gallo and Daughtry, 1986). However, the height of the banana canopy made this practically impossible. Similarly, PAR measurements in this study were taken during varying weather circumstances although working under clear skies was strived for. On overcast days, diffuse light becomes relatively more important. Weather conditions were only noted per farm and may have changed in between the measurements of different transects on the farm.

The measured girths of the banana plants were small. Only the average girth of $70 \mathrm{~cm}$ in Kanungu in 2016A is in line with findings of Wairegi et al. (2009) (mean girth of 75 and $82 \mathrm{~cm}$ in southwestern and eastern Uganda), Ntamwira et al. (2013) (about $70 \mathrm{~cm}$ ), and Nyombi et al. (2009) (68 cm at flowering and a reduction of $12 \%$ from flowering to harvest). Even though these studies included data from research stations or demonstration trials where fertilizer was applied and bananas in this experiment were all farmer managed, the measured girths still seem small. However, for the purpose of comparing the two treatments, the data give no further indication that pruning may have affected the banana yield.

Although the transects provided a rich picture in terms of light availability in the plot (Supplementary Material Appendix III), the differences in position of banana plants made a direct comparison between plots difficult. For future research, an alternative would be to take measurements at different distances from banana plants, or at random locations in the plot. Another factor to explore in future could be the effect of pruning under different mat and pseudostem densities, as they appeared to be smaller in Uganda than in DRC. This was in line with our expectations regarding better soil fertility in Uganda than in DRC, although the measured banana girths did not confirm more vigorous growth of these bananas. Conducting the research on-farm, but varying the banana densities as part of the research setup rather than working with irregular densities as planted by farmers could help to improve the results. Finally, in all studies so far, pruning while retaining to seven or eight leaves shows mixed results on climbing bean yields, and no clear economic benefit (Ocimati et al., 2019). A new factor that could be explored to improve the results of a climbing bean $\times$ banana intercropping system could therefore be to vary with the relative plant densities of both crops. Wortmann et al. (1992) concluded that the leaf area index of bush beans under bananas was smaller than for bush bean grown as a sole crop, probably because the plants were smaller and had fewer leaves per plant. Increasing plant densities under intercropping may increase climbing bean yields - which in turn needs to be assessed in relation to potential competition effects for banana.

\section{Conclusions}

To our knowledge, this study is the first to address intercropping of banana and climbing bean in the Ugandan highlands, where banana and beans are important crops for food security and people's livelihoods. Despite the field challenges associated with on-farm data collection, our study 
yielded useful insights in the effect of pruning on light availability for beans and the resulting (lack of) effect on bean yields. We found that banana leaf pruning to eight leaves enhanced PAR availability for intercropped beans, but there was only weak evidence that reduced shading positively affected climbing bean yields, and there were no significant effects of pruning on climbing bean yield. The local and improved bean variety yielded similarly in pruned and non-pruned subplots, but the local variety tended to perform relatively better in intercropping and the improved variety in sole cropping. A more specific focus on the performance of different varieties in sole and intercropping over multiple seasons could give more conclusive evidence on differences in shade tolerance between varieties. Whereas the number of banana mats and the distance between them did not influence PAR availability and bean yields, the number of pseudostems per plot did, and would be a better indicator to use in future studies. We conclude that a moderate pruning level with eight banana leaves retained improves light availability, but yield and economic benefits on the intercrop are limited. Instead, future research may explore the effects of retaining fewer leaves on both bean and banana yields in the Ugandan highlands or assess other factors that may optimize the relation between the two crops such as the relative plant densities of bean and banana.

Acknowledgements. We greatly acknowledge the help of field officers Justine Onyinge, John Ssekamwa, Rosira Kunihiira, Innocent Byamugisha, and Patrick Nyokos in trial management and data collection.

Financial Support. We thank the Bill \& Melinda Gates Foundation for partnering in this research through a grant to Wageningen University to support the project N2Africa: Putting Nitrogen Fixation to Work for Smallholder Farmers in Africa (www.N2Africa.org).

Supplementary material. For supplementary material for this article, please visit https://doi.org/10.1017/S0014479720000411

\section{References}

Akyeampong E, Hitimana L, Torquebiau E and Munyemana PC (1999). Multistrata Agroforestry with Beans, Bananas and Grevillea robusta in the Highlands of Burundi. Experimental Agriculture 35, 357-369.

Checa O, Ceballos H and Blair MW (2006). Generation means analysis of climbing ability in common bean (Phaseolus vulgaris L.). Journal of Heredity 97, 456-465.

Davis JHC and Garcia S (1983). Competitive ability and growth habit of indeterminate beans and maize for intercropping. Field Crops Research 6, 59-75.

Franke AC, Baijukya F, Kantengwa S, Reckling M, Vanlauwe B and Giller KE (2016). Poor farmers - poor yields: Socioeconomic, soil fertility and crop management indicators affecting climbing bean productivity in northern Rwanda. Experimental Agriculture https://doi.org/10.1017/S0014479716000028

Gallo KP and Daughtry CST (1986). Techniques for measuring intercepted and absorbed photosynthetically active radiation in corn canopies. Agronomy Journal 78, 752-756.

Gebeyehu S, Simane B and Kirkby R (2006). Genotype $\times$ cropping system interaction in climbing beans (Phaseolus vulgaris L.) grown as sole crop and in association with maize (Zea mays L.). European Journal of Agronomy 24, 396-403.

Giller KE and Cadisch G (1995). Future benefits from biological nitrogen fixation: An ecological approach to agriculture. Plant and Soil 174, 255-277.

Isaacs KB, Snapp SS, Kelly JD and Chung KR (2016). Farmer knowledge identifies a competitive bean ideotype for maizebean intercrop systems in Rwanda. Agriculture \& Food Security 5, 15.

Kaizzi KC, Cyamweshi AR, Kibunja CN, Senkoro C, Nkonde D, Maria R and Wortmann CS (2018). Bean yield and economic response to fertilizer in eastern and southern Africa. Nutrient Cycling in Agroecosystems 111, 47-60.

Kaizzi KC, Byalebeka J, Semalulu O, Alou IN, Zimwanguyizza W, Nansamba A, Odama E, Musinguzi P, Ebanyat P, Hyuha T, Kasharu AK and Wortmann CS (2012). Optimizing smallholder returns to fertilizer use: Bean, soybean and groundnut. Field Crops Research 127, 109-119.

MAAIF (2019). Beans Training Manual for Extension workers in Uganda. Entebbe, Uganda: Ministry of Agriculture, Animal Industry and Fisheries.

Marinus W (2015). Opportunities and constraints for climbing bean (Phaseolus vulgaris L.) cultivation by smallholder farmers in the Ugandan highlands: Developing a 'basket of options'. Wageningen: Wageningen University. Available at https://www. n2africa.org/opportunities-and-constraints-climbing-bean-phaseolus-vulgaris-1-cultivation-smallholder-farmers

Ntamwira J, Pypers P, Van Asten PJA, Vanlauwe B, Ruhigwa B, Lepoint P and Blomme G (2013). Effect of banana leaf pruning on legume yield in banana-legume intercropping systems in eastern Democratic Republic of Congo. In Blomme G, 
van Asten P, Vanlauwe B (ed), Banana systems in the humid highlands of sub-Saharan Africa: enhancing resilience and productivity. Wallingford, Oxfordshire: CABI, pp. 158-165.

Ntamwira J, Pypers P, van Asten P, Vanlauwe B, Ruhigwa B, Lepoint P, Dhed'a B, Monde T, Kamira M and Blomme G. (2014). Effect of banana leaf pruning on banana and legume yield under intercropping in farmers' fields in eastern Democratic Republic of Congo. Journal of Horticulture and Forestry 6, 72-80.

Nyombi K, Van Asten PJA, Leffelaar PA, Corbeels M, Kaizzi CK and Giller KE (2009). Allometric growth relationships of East Africa highland bananas (Musa AAA-EAHB) cv. Kisansa and Mbwazirume. Annals of Applied Biology 155, 403-418.

Ocimati W, Ntamwira J, Groot JCJ, Taulya G, Tittonell P, Dhed'a B, Asten P van, Vanlauwe B, Ruhigwa B and Blomme G. (2019). Banana leaf pruning to facilitate annual legume intercropping as an intensification strategy in the East African highlands. European Journal of Agronomy 110. https://doi.org/10.1016/j.eja.2019.125923

Ronner E, Descheemaeker K, Almekinders CJM, Ebanyat P and Giller KE (2018). Farmers' use and adaptation of improved climbing bean production practices in the highlands of Uganda. Agriculture, Ecosystems \& Environment 261, 186-200.

Snapp SS, Rohrbach DD, Simtowe F and Freeman HA (2002). Sustainable soil management options for Malawi: can smallholder farmers grow more legumes? Agriculture, Ecosystems \& Environment 91, 159-174.

Sperling L and Muyaneza S (1995). Intensifying production among smallholder farmers: the impact of improved climbing beans in Rwanda. African Crop Science Journal 3, 117-125.

Vanlauwe B, Hungria M, Kanampiu F and Giller KE (2019). The role of legumes in the sustainable intensification of African smallholder agriculture: Lessons learnt and challenges for the future. Agriculture, Ecosystems \& Environment 284, 106583.

Wairegi LWI, van Asten PJA, Tenywa M and Bekunda M (2009). Quantifying bunch weights of the East African Highland bananas (Musa spp. AAA-EA) using non-destructive field observations. Scientia Horticulturae 121, 63-72.

Wortmann CS and Sengooba T (1993). The banana-bean intercropping system - bean genotype $\times$ cropping system interactions. Field Crops Research 31, 19-25.

Wortmann CS, Sengooba T and Kyamanywa S (1992). Banana and Bean Intercropping: Factors Affecting Bean Yield and Land Use Efficiency. Experimental Agriculture 28, 287-294.

Cite this article: Ronner E, Thuijsman E, Ebanyat P, Descheemaeker K, and Giller KE (2021). Intercropping of climbing bean (Phaseolus vulgaris, L.) and East African highland banana (Musa spp.) in the Ugandan highlands. Experimental Agriculture 57, 1-14. https://doi.org/10.1017/S0014479720000411 